\title{
Data Reconciliation and Gross Error Detection for Troubleshooting of Ammonia Reactor
}

\author{
Tri Partono Adhi ${ }^{1, *}$ and Untoro Eko Saputro ${ }^{1}$ \\ ${ }^{1}$ Department of Chemical Engineering, Institut Teknologi Bandung, Jln. Ganeca No. 10, Labtek X, Bandung 40132, Indonesia
}

\begin{abstract}
Data reconciliation (DR) and gross error detection are two common tools used in industry to provide accurate and reliable data, which is useful to analyse plant performance and basis for troubleshooting. DR techniques improve the accuracy of measurements by using redundancies in material and energy balances. This provides reliable information that could help decision making regarding plant operation, which potentially leads to financial benefit. This paper presents the utilization of plant data to perform troubleshooting of ammonia reactor, in particular the profile of catalyst activity. Bad plant data are collected and then analysed using DR to produces reconciled data, which could be used to detect and identify the gross error measurements. The input data for DR and gross error detection were gathered from Aspen HYSYS V8.8 simulations by modelling the single-bed ammonia reactor. The result presents that bad plant data could define actual system condition such as gross error measurements in normal condition or catalyst activity problem. Both conditions are modelled by DR to indicate actual system condition using statistical analysis and to perform troubleshooting. Appropriate troubleshooting could save time and provide financial benefits by avoiding wrong accusation of system problem, specifically in ammonia reactor evaluated in this paper.
\end{abstract}

\section{Introduction}

The reliability of plant data could determine the effectiveness of plant performance improvement strategies. If these data are not reliable, decisions might be made based on wrong assumptions and more harm than good may occur [1]. One of the key factors of data reliability improvement is the presence of gross errors in process data. Data reconciliation and gross errors detection could provide efficiency analysis, condition monitoring and operation optimization [2]. These techniques could be beneficial for complex chemical process systems, such as those in an ammonia reactor, where gross errors and data reconciliation are useful to support troubleshooting in this system.

The inaccuracy of measuring instruments could produce gross errors and other problems could appear because of inadequate mathematical models. When a set of data is realistic, then the material and energy is almost balance [3]. Imbalance material and energy might indicate gross errors in data.

Basic issues are whether the estimation of an observed value can be improved by using the other measurements (redundancy), an unobserved value is estimable from the observed ones (determinability) and whether an observed value is a gross error [4]. Process modeling also provide best analysis tools to indicate process condition and decide solution of the problems by comparing redundancy and simulation. Computations and simulation could evaluate the system performance, obtain reconcile data (DR), or to optimize/troubleshoot the system by adjusting some parameters [5].

Good measurement usually provides data redundancy to guarantee data availability. This redundancy could be used to determine the suitable mathematical model and improve the accuracy of plant data by reducing the effect of random errors. Data reconciliation use redundant data and adjust the redundant data according to their estimated standard deviations to obtain the estimation that satisfy system constraints [2].

Data reconciliation adjusts process measurements with random errors by having them satisfy material and energy balance constraints and is a way to improve the quality of the measurements taken from a process via DCS or any other means of data collection. [6] In ammonia plant, plant data is usually provided in logbook and noted by operator, and it is also recorded in DCS system. These plant data could be used to improve the plant performance or to solve plant problems. Monitoring and analyzing bad plant data could trigger wrong troubleshooting solution which eventually could harming plant and environment. This could lead to wrong decisions that results financial loss. Gross errors are the data problems which frequently appear, so it is important to identify and isolate gross errors. Based on gross error data, the decrease plant performance could be identified, so the system could be overhauled to fix the

Corresponding author: tpadhi@.che.itb.ac.id 
performance. There may also be a possibility where the system is running well, but there are gross errors in these data because of human/operator errors, inaccurate measurement, or others problems. Bagajewicz explain that some measurements are highly vulnerable to the presence of undetected biases where induced biases are larger than the standard deviation (i.e. precision) many times [7].

There are two main problems in an ammonia reactor system analyzed in this paper, namely the gross error problem and the decreasing of ammonia reactor catalyst activity. This paper presents and demonstrates a brief utilization of plant data to analyze and troubleshooting of ammonia synthesis reactor single bed. Ammonia reactor could be simplified as single bed reactor to ease the analysis or data reconciliation.

\section{Methodology}

The problem of data reconciliation in plant is to minimize an objective function, e.g. the sum of the squared adjusts pondered by their reciprocal variances, subject to linear or nonlinear restrictions (material balances) [8]. Reconciled process data is used to specify the current status of the plant model and for estimation of the model parameters for plant-model matching [6]. Steady state simulation packages equipped with optimization routines can be used to perform data reconciliation and obtain accurate results. This approach can be used to reconcile linear and nonlinear problems via the minimization of a weighted least squares objective function by varying appropriate flowsheet variables [9]. So, data reconciliation problem simulation is defined as a nonlinear steady-state data by a least sum of square minimization problem as follows:

\section{Error! Reference source not found. $f\left(x_{i}, y_{i}\right)=0$}

$\mathbf{Q}_{\min }$ is the estimated covariance matrix of measured data; $\mathbf{x}^{\mathbf{m}}$ is the measured values; $\mathbf{x}_{\mathbf{i}}$ is the reconciled values of measured parameters; and $\sigma_{i}$ represents the estimated error standard deviation. $\mathbf{f}(\mathbf{x}, \mathbf{y})$ represents the steady state system constraint equations; $\mathbf{y}_{\mathbf{i}}$ represents the calculated value for the unmeasured parameters.

Process simulators with optimization capabilities such as Aspen HYSYS can be used to carry out data reconciliation and parameter estimation [9]. Data reconciliation and gross error detection are simulated using Aspen HYSYS V8.8 to achieve efficient calculation including measurement design, gross error detection and elimination, errors propagation, as well as parameters estimation. Data and model are compared to determine an adequate model by formulation as follows:

$$
Q_{\text {min }} \approx \chi_{\text {crit }}^{2}(v)
$$

$\mathbf{Q}_{\min }$ represents the random variables with distribution of $\chi^{2}$, and $\mathbf{v}$ represents the degree of freedom. If $\mathrm{Q}_{\text {min }}$ is greater than critical value of distribution $\chi^{2}\left(\sigma_{\mathrm{c}}\right)$, it indicates that data and model are conflicted which could not be ignored (significant factor). The basis of design of ammonia reactor modeling in Aspen HYSYS uses kinetic data by Temkin equation. Ammonia synthesis is an exothermic reaction with kinetic equation which are defined by following equations:

$$
\begin{gathered}
\mathrm{N}_{2(\mathrm{~g})}+3 \mathrm{H}_{2(\mathrm{~g})} \leftrightarrow 2 \mathrm{NH}_{3(\mathrm{~g})} \Delta \mathrm{H}=-92,22 \mathrm{~kJ} / \mathrm{mol} \\
\text { Error! Reference source not found. }
\end{gathered}
$$

Error! Reference source not found.

\section{Error! Reference source not found.Error! Reference source not found. (7)}

Feed composition and conditions are shown in table 1. Ammonia synthesis reactor is presented in table 1. The simulation in Aspen HYSYS V8.8 uses Peng-Robinson Package and the ammonia reactor single bed is modeled as a single adiabatic plug flow reactor.

Table 1. Composition and feed conditions of reactor

\begin{tabular}{|l|c|}
\hline Temperature $\left({ }^{\circ} \mathrm{C}\right)$ & 437 \\
\hline Pressure $(\mathrm{bar})$ & 142.1 \\
\hline Flowrate $(\mathrm{kg} / \mathrm{h})$ & 203422 \\
\hline Flowrate $(\mathrm{kmol} / \mathrm{h})$ & 19440 \\
\hline Vapour Fraction & 1.00 \\
\hline Composition $(\%-\mathrm{mol})$ & \\
\hline $\mathrm{N}_{2}$ & 17.77 \\
\hline $\mathrm{H}_{2}$ & 63.77 \\
\hline $\mathrm{NH}_{3}$ & 8.81 \\
\hline $\mathrm{CH}$ & 4.82 \\
\hline $\mathrm{Ar}$ & 4.82 \\
\hline
\end{tabular}

Table 2. Composition and feed condition of reactor

\begin{tabular}{|l|c|}
\hline Name & $\mathrm{R}-100$ \\
\hline Volume reactor $\left(\mathrm{m}^{3}\right)$ & 13.96 \\
\hline Length $(\mathrm{m})$ & 6 \\
\hline Diameter $(\mathrm{m})$ & 1.721 \\
\hline Void fraction & 0.36 \\
\hline Type of reactor & Adiabatic Plug Flow Reactor \\
\hline
\end{tabular}

Data reconciliation is assumed as single jeopardy. It means that there are no two or more problems and gross errors that are occurred simultaneously. The other assumption is there is no channeling in ammonia reactor system, as the focuses of this paper are gross error measurements and the decreasing of catalyst activity. Based on these data and assumptions, the methodology is divided into 4 main steps, as follows:

1. Ideal modelling using Aspen HYSYS and operation/plant data collection. This model is based on design data with standard deviation of measurement devices. Operational data is acquired from operator shift with data redundancy.

2. Data analysis and gross error identification and isolation. Data reconciliation uses ideal model and operational/plant data to obtain reconciled data. Error from reconciled data and plant data is compared to standard deviation of measurement devices. If the error is greater than standard deviation, gross error identification and isolation are next step to determine 
system conditions. Once a gross error was detected, a new regression was performed and tests were done until the data were free of errors [11].

3. Troubleshooting with measured data which don't have gross errors. If there are no gross errors, a new model was generated that is appropriate to the problem in system. Measured data will be checked with new model and produce reconciled data. If error is within the standard deviation range and identical with the new model, thus the system experiences a problem based on the model.

4. Decision making. Based on data reconciliation and troubleshooting, solutions are given based on analysis. For example, catalyst regeneration is proposed if there is a catalyst deactivation. The other example of a recommendation to check and calibrate the instrumentation if there are gross errors. The detailed methodology is shown in figure 1 .

\section{Result and Discussion}

Ideal model based on design data from plant is shown in figure 2. Result of streams inlet and outlet is shown in table 3. Specification of measurement devices in reactor system is presented in table 4 .

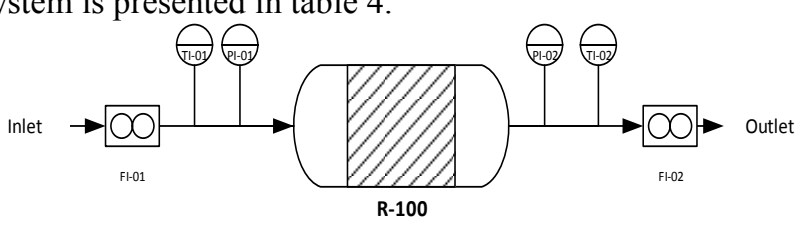

Figure 1. Ideal model of ammonia synthesis reactor

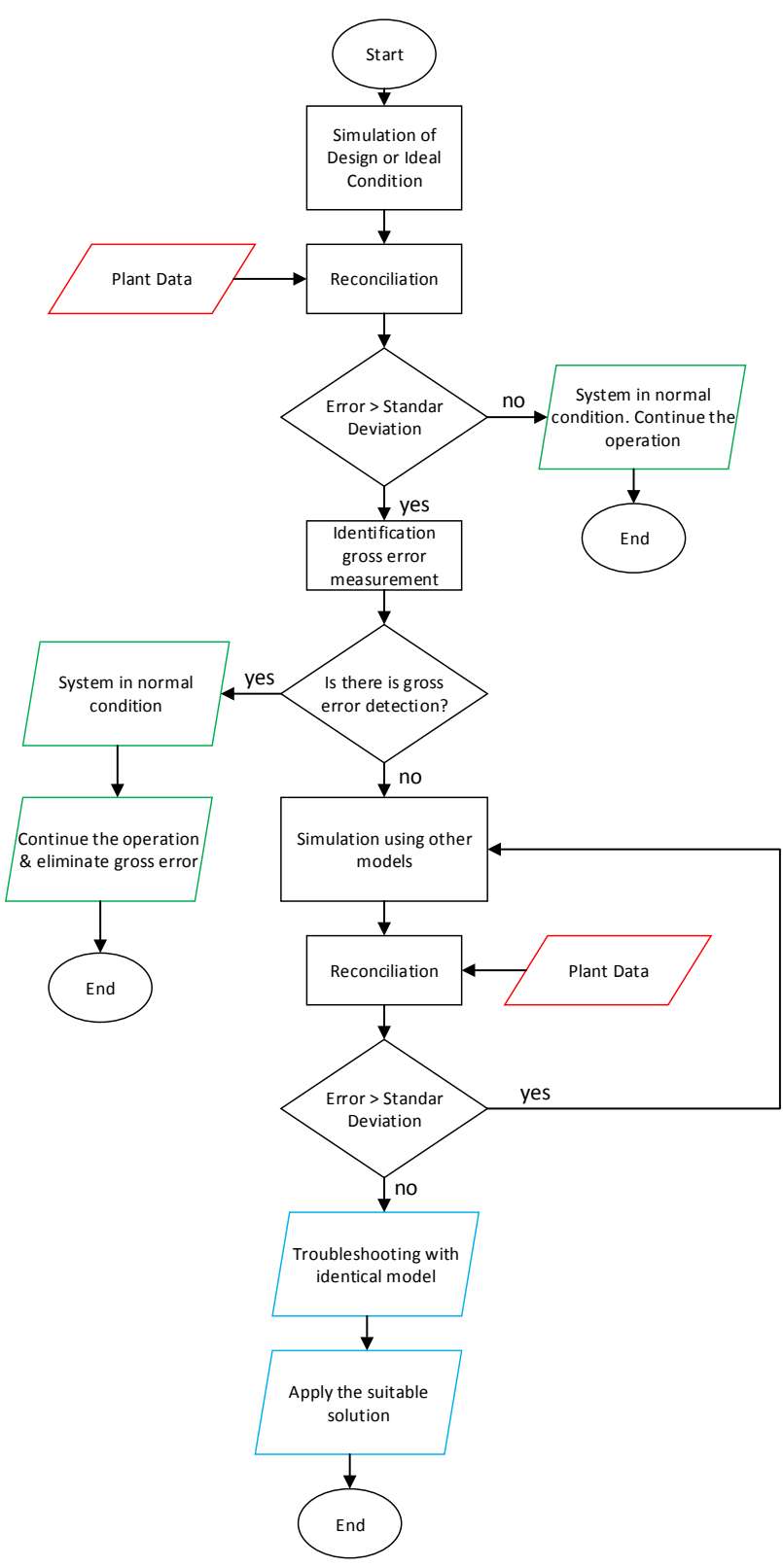

Figure 1. Methodology of simulation data reconciliation for troubleshooting

Table 3. Stream specification of ideal model reactor

\begin{tabular}{|l|c|c|}
\hline Stream & Inlet & Outlet \\
\hline Temperature $\left({ }^{\circ} \mathrm{C}\right)$ & 437 & 492.3 \\
\hline Pressure (bar) & 142.1 & 141.7 \\
\hline Flow $(\mathrm{kg} / \mathrm{h})$ & 203422 & 203422 \\
\hline Flow (kmol/h) & 19440 & 187788 \\
\hline Vapour fraction & 1.00 & 1.00 \\
\hline Composition (\%-mol) & & \\
\hline $\mathrm{N}_{2}$ & 17.77 & 16.65 \\
\hline $\mathrm{H}_{2}$ & 63.77 & 60.76 \\
\hline $\mathrm{NH}_{3}$ & 8.81 & 12.61 \\
\hline $\mathrm{CH}_{4}$ & 4.82 & 4.99 \\
\hline $\mathrm{Ar}$ & 4.82 & 4.99 \\
\hline
\end{tabular}


Table 4. Measurement devices specification of reactor system

\begin{tabular}{|c|c|c|c|c|c|}
\hline $\begin{array}{c}\text { Tag } \\
\text { Number }\end{array}$ & Type & Unit & Min & Max & $\begin{array}{l}\text { St. } \\
\text { Dev. }\end{array}$ \\
\hline FI-01 & $\begin{array}{l}\text { Online } \\
\text { analyser }\end{array}$ & $(\mathrm{kmol} / \mathrm{h})$ & 5000 & 20000 & $\frac{ \pm}{100}$ \\
\hline FI-02 & $\begin{array}{c}\text { Online } \\
\text { analyser }\end{array}$ & $(\mathrm{kmol} / \mathrm{h})$ & 5000 & 20000 & $\stackrel{ \pm}{100}$ \\
\hline TI-01 & $\begin{array}{l}\text { Temperature } \\
\text { indicator }\end{array}$ & $\left({ }^{\circ} \mathrm{C}\right)$ & 300 & 500 & \pm 1 \\
\hline TI-02 & $\begin{array}{l}\text { Temperature } \\
\text { indicator }\end{array}$ & $\left({ }^{\circ} \mathrm{C}\right)$ & 300 & 500 & \pm 1 \\
\hline PI-01 & $\begin{array}{l}\text { Pressure } \\
\text { Indicator }\end{array}$ & (bar) & 125 & 200 & \pm 1 \\
\hline PI-02 & $\begin{array}{l}\text { Pressure } \\
\text { Indicator }\end{array}$ & (bar) & 125 & 200 & \pm 1 \\
\hline
\end{tabular}

\subsection{Gross Error Detection and Elimination}

Hypothetical plant data are acquired as shown in table 5 with 3 redundancies. Data reconciliation result from this plant data is shown in table 6 .

Table 5. Plant data from ammonia synthesis reactor

\begin{tabular}{|c|c|c|}
\hline Time & 08.00 & 12.00 \\
\hline FI-01 $\left(\mathrm{H}_{2}\right)(\mathrm{kmol} / \mathrm{h})$ & 12410 & 12420 \\
\hline FI-02 $\left(\mathrm{H}_{2}\right)(\mathrm{kmol} / \mathrm{h})$ & 17988 & 17955 \\
\hline $\mathrm{TI}-01\left({ }^{\circ} \mathrm{C}\right)$ & 436.1 & 436.9 \\
\hline TI-02 $\left({ }^{\circ} \mathrm{C}\right)$ & 493 & 492.6 \\
\hline PI-01 (bar) & 142.5 & 142.5 \\
\hline PI-02 (bar) & 142.1 & 141.9 \\
\hline
\end{tabular}

Table 6. Data reconciliation result of plant data

\begin{tabular}{|c|c|c|c|c|c|c|}
\hline Time & Tag & Plant data & Std. Dev. & Reconciled Data & Design Data & Error/Std. Dev. (\%) \\
\hline 08.00 & FI-01 $\left(\mathrm{H}_{2}\right)(\mathrm{kmol} / \mathrm{h})$ & 12410 & 100 & 12397 & 12397 & 12.89 \\
\cline { 2 - 7 } & FI-02 $\left(\mathrm{H}_{2}\right)(\mathrm{kmol} / \mathrm{h})$ & 17988 & 100 & 11415 & 11412 & 6573.15 \\
\cline { 2 - 7 } & $\mathrm{TI}-01\left({ }^{\circ} \mathrm{C}\right)$ & 436.1 & 1 & 436.8 & 437 & 67.08 \\
\cline { 2 - 7 } & $\mathrm{TI}-02\left({ }^{\circ} \mathrm{C}\right)$ & 492.4 & 1 & 491.9 & 492.3 & 51.09 \\
\cline { 2 - 7 } & $\mathrm{PI}-01(\mathrm{bar})$ & 142.5 & 1 & 142.1 & 142.1 & 37.13 \\
\cline { 2 - 7 } & $\mathrm{PI}-02(\mathrm{bar})$ & 142.1 & 1 & 141.7 & 141.7 & 37.13 \\
\hline 12.00 & $\mathrm{FI}-01\left(\mathrm{H}_{2}\right)(\mathrm{kmol} / \mathrm{h})$ & 12420 & 100 & 12397 & 12397 & 22.89 \\
\cline { 2 - 7 } & FI-02 $\left(\mathrm{H}_{2}\right)(\mathrm{kmol} / \mathrm{h})$ & 17955 & 100 & 11415 & 11412 & 6540.08 \\
\cline { 2 - 7 } & $\mathrm{TI}-01\left({ }^{\circ} \mathrm{C}\right)$ & 436.9 & 1 & 436.8 & 437 & 13.68 \\
\cline { 2 - 6 } & $\mathrm{TI}-02\left({ }^{\circ} \mathrm{C}\right)$ & 492.6 & 1 & 491.9 & 492.3 & 38.25 \\
\cline { 2 - 6 } & $\mathrm{PI}-01(\mathrm{bar})$ & 142.5 & 1 & 142.1 & 142.1 & 18.52 \\
\cline { 2 - 6 } & $\mathrm{PI}-02(\mathrm{bar})$ & 141.9 & 1 & 141.7 & 14.7 & 14.10 \\
\hline \multicolumn{7}{|c|}{$\chi_{\min }(\mathrm{Objective} \mathrm{Function)}$} \\
\hline
\end{tabular}

Table 7. Data reconciliation result of plant data after gross error elimination

\begin{tabular}{|c|c|c|c|c|c|c|}
\hline Time & Tag & Plant data & Std. Dev. & Reconciled Data & Design Data & Error/Std. Dev. (\%) \\
\hline \multirow[t]{6}{*}{08.00} & FI-01 $\left(\mathrm{H}_{2}\right)(\mathrm{kmol} / \mathrm{h})$ & 12410 & 100 & 12397 & 12397 & 12.89 \\
\hline & FI-02 $\left(\mathrm{H}_{2}\right)(\mathrm{kmol} / \mathrm{h})$ & 17988 & 100000 & 11415 & 11412 & 6.57 \\
\hline & TI-01 $\left({ }^{\circ} \mathrm{C}\right)$ & 436.1 & 1 & 436.8 & 437 & 67.08 \\
\hline & TI-02 $\left({ }^{\circ} \mathrm{C}\right)$ & 492.4 & 1 & 491.9 & 492.3 & 51.09 \\
\hline & PI-01 (bar) & 142.5 & 1 & 142.1 & 142.1 & 37.13 \\
\hline & PI-02 (bar) & 142.1 & 1 & 141.7 & 141.7 & 37.13 \\
\hline \multirow[t]{6}{*}{12.00} & FI-01 $\left(\mathrm{H}_{2}\right)(\mathrm{kmol} / \mathrm{h})$ & 12420 & 100 & 12397 & 12397 & 22.89 \\
\hline & FI-02 $\left(\mathrm{H}_{2}\right)(\mathrm{kmol} / \mathrm{h})$ & 17955 & 100000 & 11415 & 11412 & 6.54 \\
\hline & TI-01 $\left({ }^{\circ} \mathrm{C}\right)$ & 436.9 & 1 & 436.8 & 437 & 13.68 \\
\hline & TI-02 $\left({ }^{\circ} \mathrm{C}\right)$ & 492.6 & 1 & 491.9 & 492.3 & 72.25 \\
\hline & PI-01 (bar) & 142.5 & 1 & 142.1 & 142.1 & 38.52 \\
\hline & PI-02 (bar) & 141.9 & 1 & 141.7 & 141.7 & 18.52 \\
\hline \multicolumn{6}{|c|}{$\mathrm{Q}_{\min }$ (Objective Function) } & 1.78 \\
\hline \multicolumn{6}{|c|}{$\chi^{2}(v)=\sigma_{c}$} & 14.10 \\
\hline
\end{tabular}

Based on table 6, measurement devices FI-02 has high error but others measurement devices still have tolerable error. These data show that the hydrogen content in the product stream is greater than that in the feed stream. The hypothesis is there is gross error measurement in FI-02 and FI-02 measurement is ignored to identify and isolate the gross error. Data reconciliation after gross error elimination of FI-02 measurement is shown in table 7.

Gross error elimination could minimize objective function $\left(\mathrm{Q}_{\min }\right)$ from 8599.67 to 1.78 . It indicates that there is gross error measurement in FI-02. So, there is no problem occurred in ammonia reactor based on this analysis because the error from data reconciliation of plant data after gross error elimination is still tolerable. 
Action required based on this analysis are instrument FI02 overhaul and calibration, procedure checking of FI-02 measurement by operator (it could be human error, e.g. value which is measured by FI-02 is not molar flow of $\mathrm{H}_{2}$ but total molar flow).

\subsection{Gross Error Detection for Modelling and Troubleshooting}

The decreasing of temperature outlet reactor could be caused by deactivation of catalyst or gross error measurement. Catalyst as one of main component in reactor could determine the conversion and the outlet temperature of reactor. Higher activity catalyst could lead to higher conversion and higher temperature outlet of exothermic adiabatic reactor.

Data reconciliation and gross error detection could analyse the model of system problems. Hypothetical bad plant data were acquired as shown in table 8 . It indicates that there were problems in the ammonia reactor because of temperature outlet drop. Temperature measurements have one redundancy because reactor specification and kinetic data is known, so TI-02 would be calculated by model.

Table 8. Plant data of ammonia reactor

\begin{tabular}{|l|l|l|l|l|}
\hline Tag & $\begin{array}{l}\text { TI-01 } \\
\left({ }^{\circ} \mathrm{C}\right)\end{array}$ & $\begin{array}{l}\text { TI-02 } \\
\left({ }^{\circ} \mathrm{C}\right)\end{array}$ & $\begin{array}{l}\text { FI-01 } \\
(\mathrm{kmol} / \mathrm{h})\end{array}$ & $\begin{array}{l}\text { FI-02 } \\
(\mathrm{kmol} / \mathrm{h})\end{array}$ \\
\hline Design Data & 437 & 492.3 & 12397 & 11412 \\
\hline Plant Data 1 & 436.5 & 481 & 12396 & 11414 \\
\hline Plant Data 2 & 436.8 & 480.7 & 12395 & 11411 \\
\hline
\end{tabular}

Based on these plant data, the data reconciliation result (using Aspen HYSYS simulation) based on ideal model is shown in table 9.

Table 9. Ideal model data reconciliation

\begin{tabular}{|c|c|c|c|c|c|c|}
\hline Type & Tag & $\begin{array}{c}\text { Plant } \\
\text { data }\end{array}$ & $\begin{array}{c}\text { Std. } \\
\text { Dev. }\end{array}$ & $\begin{array}{c}\text { Recon } \\
\text { Data }\end{array}$ & $\begin{array}{c}\text { Design } \\
\text { Data }\end{array}$ & $\begin{array}{c}\text { Error/Std. } \\
\text { Dev. }(\%)\end{array}$ \\
\hline $\begin{array}{c}\text { Plant } \\
\text { Data 1 }\end{array}$ & $\begin{array}{c}\text { TI-01 } \\
\left({ }^{\circ} \mathrm{C}\right)\end{array}$ & 436.5 & 1 & 431.4 & 437 & 514.2 \\
\hline $\begin{array}{c}\text { Plant } \\
\text { Data 2 }\end{array}$ & $\begin{array}{c}\text { TI-01 } \\
\left({ }^{\circ} \mathrm{C}\right)\end{array}$ & 436.8 & 1 & 431.5 & 437 & 534.4 \\
\hline $\begin{array}{c}\text { Plant } \\
\text { Data 1 }\end{array}$ & $\begin{array}{c}\text { TI-02 } \\
\left({ }^{\circ} \mathrm{C}\right)\end{array}$ & 481 & 1 & 488.9 & 492.3 & 789.5 \\
\hline $\begin{array}{c}\text { Plant } \\
\text { Data 2 }\end{array}$ & $\begin{array}{c}\text { TI-02 } \\
\left({ }^{\circ} \mathrm{C}\right)\end{array}$ & 480.7 & 1 & 490 & 492.3 & 826.0 \\
\hline \multicolumn{6}{|c|}{ Objective Function $\left(\mathrm{Q}_{\min }\right)$} & 185.55 \\
\hline \multicolumn{6}{|c|}{$\chi^{2}(v)=\sigma_{c}$} & 3.84 \\
\hline
\end{tabular}

Based on this analysis, the gross error detection should be detected in TI- 02 because of gap between plant data and design data, but data reconciliation result show that there were gross error measurements at TI-01 and TI-02. Then, the plant data is actual and there is no gross error measurements after actual checking in field data. Then, data reconciliation result also present that there is a conflict between data and model which could not be ignored because Qmin $>\sigma_{\mathrm{c}}$. So, the ideal model is not suitable for this cases.

Further analysis is shown by simulation of other models; the decreasing of catalyst activity model is one suspect of this problems. This model represent the probability of catalyst activity drop. Full activity catalyst $(100 \%)$ is simulated by default kinetic data, which is shown in table 10 .

Table 10. Catalyst activity model of ammonia reactor

\begin{tabular}{|c|c|c|c|}
\hline $\begin{array}{c}\text { Default } \\
\text { kinetic } \\
\text { data }\end{array}$ & \multicolumn{3}{|c|}{$\mathrm{k}_{1}=36421 \exp \left(\frac{-19484}{\mathrm{RT}}\right)$} \\
$\mathrm{k}_{-1}=3,4585.10^{14} \exp \left(\frac{-38119}{\mathrm{RT}}\right)$ & \\
\hline $\begin{array}{c}\text { Activity } \\
(\%)\end{array}$ & $\mathrm{A}_{1}$ & $\mathrm{~A}_{-1}$ & $\begin{array}{c}\text { Drop } \\
(\%)\end{array}$ \\
\hline 100 & 36421 & $3.4585 \times 10^{14}$ & 0 \\
\hline $\begin{array}{c}\mathrm{a} \\
\text { (model) }\end{array}$ & $\mathrm{a} \% \times 36421$ & $\begin{array}{c}\mathrm{a} \% \times \\
3.4585 \times 10^{14}\end{array}$ & $100-\mathrm{a}$ \\
\hline
\end{tabular}

This catalyst model is modelled using spreadsheet feature in Aspen HYSYS to define the parameter in data reconciliation. Data reconciliation result of decreasing catalyst activity model is shown in table 11 .

Table 11. Catalyst activity model data reconciliation

\begin{tabular}{|c|c|c|c|c|c|c|}
\hline & Tag & $\begin{array}{c}\text { Plant } \\
\text { data }\end{array}$ & $\begin{array}{c}\text { Std. } \\
\text { Dev. }\end{array}$ & $\begin{array}{c}\text { Recon } \\
\text { Data }\end{array}$ & $\begin{array}{c}\text { Design } \\
\text { Data }\end{array}$ & $\begin{array}{c}\text { Error/Std. } \\
\text { Dev. }(\%)\end{array}$ \\
\hline $\begin{array}{c}\text { Plant } \\
\text { Data 1 }\end{array}$ & $\begin{array}{c}\text { TI-01 } \\
\left({ }^{\circ} \mathrm{C}\right)\end{array}$ & 436.5 & 1 & 436.7 & 437 & 15.90 \\
\hline $\begin{array}{c}\text { Plant } \\
\text { Data 2 }\end{array}$ & $\begin{array}{c}\text { TI-01 } \\
\left({ }^{\circ} \mathrm{C}\right)\end{array}$ & 436.8 & 1 & 436.6 & 437 & 15.89 \\
\hline $\begin{array}{c}\text { Plant } \\
\text { Data 1 }\end{array}$ & $\begin{array}{c}\text { TI-02 } \\
\left({ }^{\circ} \mathrm{C}\right)\end{array}$ & 481 & 1 & 480.9 & 492.3 & 13.18 \\
\hline $\begin{array}{c}\text { Plant } \\
\text { Data 2 }\end{array}$ & $\begin{array}{c}\text { TI-02 } \\
\left({ }^{\circ} \mathrm{C}\right)\end{array}$ & 480.7 & 1 & 490.8 & 492.3 & 14.76 \\
\hline \multicolumn{6}{|c|}{ Objective Function $\left(\mathrm{Q}_{\min }\right)$} & 0.09 \\
\hline \multicolumn{6}{|c|}{$\chi^{2}(v)=\sigma_{c}$} & 3.84 \\
\hline
\end{tabular}

Based on further analysis, gross error detection isn't found at TI-01 and TI-02. Data reconciliation result also present that model is suitable for this cases because of Qmin $<\sigma_{\mathrm{c}}$. Case study simulation in Aspen HYSYS analysis is simulated to ensuring the problem of the decreasing catalyst activity. The result of case study between model catalyst activity to outlet temperature reactor is shown in figure 3 .

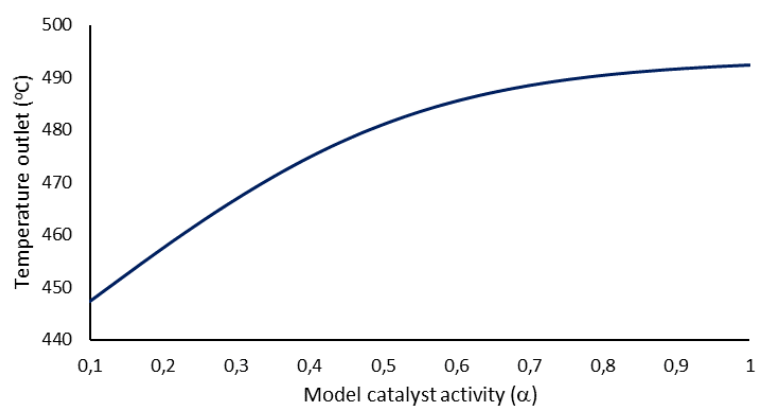

Figure 3. Case study of model catalyst activity to temperature outlet reactor

Based on case study and data reconciliation comparison, the problem of this system is the decreasing of catalyst activity. The data fitting feature shows that the activity of the catalyst is only $50.19 \%$ of full activity and it approaches the value of temperature outlet at $50 \%$ catalyst activity based on the case study model. These data also match to real condition because catalyst need 
regeneration in next several months based on plant data collection time. So, the troubleshooting solution of this problem is to regenerate the catalyst in the next turn around (or sooner). This study prove that data reconciliation could provide right troubleshooting based on bad plant data, this study also shows that data reconciliation is particularly true for strategies that rely on first-principles models of the chemical plant, such as model predictive control [12] or real-time optimization [13] and combining with simulation to define faster solution of troubleshooting could save time and financial benefit.

\section{Conclusion}

In this study, data reconciliation and gross error detection are used as valuable techniques to improve the reliability of plant data, especially for troubleshooting or plant performance improvement purpose. The ammonia synthesis reactor system with redundancy measurements could be analysed by data reconciliation using Aspen HYSYS V8.8 simulations. Bad plant data that could lead to ineffective troubleshooting solutions are fitted with simulation model of data reconciliation. Gross error measurements could be identified and eliminated through data reconciliation and define system condition (in normal or trouble condition). Data reconciliation and gross error detection could provide optimum troubleshooting solutions and may result in operational and financial benefits by mitigating wrong actions due to unreliable data.

\section{References}

1. S. Guo, P. Liu, \& Z. Li., Applied Energy, Volume 165, 1037-1051(2016)

2. X. Jiang, P. Liu, \& Z. Li. Energy, Volume 75, 14-23 (2014)

3. V. S. Verneuil, P. Yang, \& F.. Chemical Engineering Progress. October 1992 (45-51)

4. R. Maronna \& J. Arcas.. Computers and Chemical Engineering 33 (2009) 65-71

5. H. Ijaz, U.M.K. Ati, \& V. Mahalec.. Applied Thermal Engineering 52 (2013) 328 - 335

6. D.B. Ozyurt \& R.B. Pike.. Computers and Chemical Engineering 28 (2004) 381 - 402

7. M.J. Bagajewicz \& D.Q. Nguyen., Computer and Chemical Engineering 32 (2008) 1257-1269

8. J. Placido, A.A. Campos, \& D.F. Monteiro. Data Reconciliation Practice at a Petroleum Refinery Company in Brazil, 10th International Symposium on Process System Engineering - PSE2009 (2009) 777-782

9. M. Piccolo \& P.L. Douglas., Asia-Pasific Journal of Chemcial Engineering Volume 4 Issue 3-4 (1996) 157-182
10. A. Rafiee, \& F. Behrouzshad., Journal of Natural Gas Science and Engineering 31 (2016) 538 - 545

11. J.S. Albuquerque, \& L.T. Biegler. Process System Engineering, AIChE Journal Vol. 42, No. 10 (1996) 2841-2856.

12. J.B. Rawlings \& B.R. Bakshi. Computer and Chemical Engineering, Volume 30, Issues 10-12 (2006) 1529 - 1541.

13. J.F. Forbes \& T.E. Marlin. Computer and Chemical Engineering, Volume 20, Issues 6-7 (1996) 717 734 